\title{
RELAÇÕES ÉTNICO-RACIAIS, DIREITOS HUMANOS E AÇÕES AFIRMATIVAS
}

\author{
ETHNIC-RACIAL RELATIONS, HUMAN RIGHTS AND AFFIRMATIVE ACTIONS \\ RELACIONES ETNICO-RACIALES, DERECHOS HUMANOS Y ACCIONES AFIRMATIVAS \\ Nara Zari Lemos Budiño \\ Mestre em Educação Profissional e Tecnológica pela UFSM, Santa Maria-RS, Brasil. E-mail: \\ Zari67hst@gmail.com. \\ Orcid: 0000-0001-8672-4533. \\ Roselene Moreira Gomes Pommer \\ Doutora em História pela UNISINOS, CTISM/UFSM, Santa Maria-RS, Brasil. E-mail: \\ roselenepommer@ctism.ufsm.br. \\ Orcid: 0000-0001-9380-7003.
}

\begin{abstract}
RESUMO
Esse artigo nasceu a partir de um recorte da dissertação de mestrado "Ações Afirmativas para a Educação Profissional e Tecnológica: Negros e Negra no Colégio Técnico Industrial de Santa Maria” apresentada ao Programa de Pós-graduação em Educação Profissional e Tecnológica da Universidade Federal de Santa MariaRS. Nesse sentido o presente trabalho parte a análise da Lei 10.639/03, que tornou obrigatório o ensino da História e da Cultura Afro-brasileira e da história da África em todos os níveis da educação básica, em escolas públicas e privadas de todo o Brasil. As ações afirmativas no campo educacional vislumbram, também, a reserva de vagas para o ingresso de estudantes que se autodeclarassem pretos ou pardos nas instituições federais de ensino técnico de nível médio, consoante a Lei $n^{\circ} 12.711 / 12$. Tendo como fonte de pesquisa o Plano Nacional de Educação em Direitos Humanos, no item que contempla a igualdade racial, fez-se uma análise das ações afirmativas e sua pertinência no que tange aos direitos humanos no âmbito da sociedade brasileira.
\end{abstract}

Palavras-chave: Educação profissional e tecnológica. História e cultura afro-brasileira. Reserva de vagas.

\begin{abstract}
This article was born from an excerpt from the master's thesis "Affirmative Actions for Professional and Technological Education: Blacks and Blacks at the Colégio Técnico Industrial de Santa Maria" presented to the Graduate Program in Professional and Technological Education at the Federal University of Santa MariaRS. In this sense, the present work starts with the analysis of Law 10.639 / 03, which made the teaching of Afro-Brazilian History and Culture and the history of Africa mandatory at all levels of basic education, in public and private schools throughout Brazil. Affirmative actions in the educational field also envisage the reservation of places for the admission of students who declare themselves to be black or brown in federal institutions of secondary technical education, according to Law No. 12,711 / 12. Using the National Plan for Education in Human Rights as a research source, in the item that contemplates racial equality, an analysis of affirmative actions and their relevance with regard to human rights within the scope of Brazilian society was carried out.
\end{abstract}

Keywords: Professional and technological education. Afro-brazilian history and culture. Reservation of vacancies.

\section{RESUMEN}

Este artículo nació de un extracto de la disertación de maestría "Acciones afirmativas para la educación profesional y tecnológica: negros y negros en el Colegio Técnico Industrial de Santa María" presentada al Programa de Posgrado en Educación Profesional y Tecnológica en la Universidad Federal de Santa Maria-RS. En este sentido, el presente trabajo inicia el análisis de la Ley 10.639 / 03, que hizo obligatoria la enseñanza 
de la historia y cultura afrobrasileña y la historia de África en todos los niveles de educación básica, en escuelas públicas y privadas de todo Brasil. Las acciones afirmativas en el campo educativo también prevén la reserva de lugares para la admisión de estudiantes que se declaran negros o morenos en las instituciones federales de educación técnica de la escuela secundaria, de acuerdo con la Ley N¹2.711/12. Utilizando el Plan Nacional de Educación en Derechos Humanos como fuente de investigación, en el ítem que contempla la igualdad racial, se realizó un análisis de las acciones afirmativas y su relevancia con respecto a los derechos humanos en el ámbito de la sociedad brasileña.

Palabras clave: Educación profesional y tecnológica. Historia y cultura afrobrasileña. Reserva de vacantes.

\section{INTRODUÇÃO}

As ações afirmativas referentes a reserva de vagas para estudantes, têm se mostrado um importante instrumento para a inclusão de negros e negras ao ensino técnico e superior. Isso por que, a questão exige não somente a inclusão pura e simples ou a sua garantia, mas também, a percepção de que as diferenças de oportunidades, entre cidadãos brasileiros foram, e continuam sendo, resultados da diferenciação entre as classes sociais que o sistema capitalista, na sua implantação tardia ao contexto de produção do Brasil, gerou. Sendo assim, é preciso garantir a permanência de estudantes negros e negras ao sistema de ensino público através de uma educação inclusiva e libertadora, para a qual a consciência de classe tem fundamental papel.

Nesse sentido, o ensino da história e da cultura afro-brasileira deverá ter como objetivo diminuir as distâncias sociais existentes entre os brasileiros. Distâncias gestadas nas relações de uma sociedade de herança escravista, de um processo capitalista dependente que divide o trabalho entre intelectual reflexivo e manual operativo, fazendo do racismo um mecanismo de dominação política.

Os profissionais da educação devem estar preparados para relacionar os conteúdos de suas diversas áreas com esses temas. Práticas discriminatórias em sala de aula e/ou condutas que podem ocorrer de forma velada ou explícita, costumam estar abrigadas por uma relação de poder, pautadas na dominação de uma classe sobre outra.

Para todos os estudantes da educação profissional e tecnológica, independente de grupo étnico, se faz necessária abordagens da História e da Cultura Afro-brasileira, apesar dos diversos caminhos profissionais que poderão seguir. Porém, a grande maioria desses deparar-se-ão com situações de discriminação racial. Mesmo que a educação para as questões étnico raciais não extirpe a discriminação, ela poderá contribuir para a formação de cidadãos mais conscientes, que possam se ver, uns nos outros, respeitando suas 
diferenças. Sobretudo, cidadãos que percebam o racismo de forma estrutural, como herança de uma cultura histórica escravista. questão é pertinente na medida em que os comportamentos discriminatórios se reproduzem nas relações de trabalho, logo, os futuros profissionais deverão saber lidar com tais situações, compreendendo-as como uma violação aos direitos humanos.

A justificativa para o presente trabalho se dá, também, pelo momento político que nosso país vivencia, caracterizado pela desvalorização dos movimentos sociais e pelo enaltecimento de doutrinas ideológicas de extrema direita, as quais elegeram, em 2016, para as Câmaras Municipais, muitos jovens negros e negras. Ocorre que, em sua maioria, esses legisladores eleitos trazem em seus discursos o ideário da classe média branca, pautado no preconceito, na meritocracia e na afirmação de que as reservas de vagas e outras conquistas têm servido para vitimizar os grupos de negros, encobrindo a luta de classes que perpassa toda a história dos negros e negras no país.

O objetivo geral do presente trabalho é a análise das ações afirmativas, com fulcro no Plano Nacional de Educação em Direitos Humanos. No que tange aos objetivos específicos, far-se-á uma análise sobre a importância das ações afirmativas no âmbito da educação profissional e tecnológica, tendo em vista o ingresso de alunos negras e negros a partir do ano de 2013 (Lei 12.711/12) e o ensino de história e cultura afro-brasileira e história da África como um mote para educação antirracista.

O artigo foi divido em duas partes: na primeira, será feita uma abordagem geral sobre o Plano Nacional para Educação em Direitos Humanos e o Programa Mundial de Educação em Direitos Humanos (PMEDH). Considerando a multiplicidade de subtemas que envolvem a temática dos direitos humanos, elencados no PMEDH, abordaremos tão somente as questões étnico-raciais. A segunda parte dedica-se as questões históricas que levaram os negros a subalternidade e o racismo estrutural da nossa sociedade.

A metodologia utilizada foi a análise histórico-crítica, tendo como base o movimento e as contradições da sociedade através da luta de classes. Esse método permite uma reflexão histórica sobre as questões raciais no Brasil e sobre a atuação dos movimentos negros em prol da conquista de tais direitos, a partir das contradições entre o racismo estrutural e sua negação através do mito da democracia racial. Partindo desses pontos, será possível demonstrar a razão da necessidade da reserva de vagas para os 
estudantes negros e negras e a promoção de uma educação antirracista, visando a construção de uma sociedade mais justa e igualitária.

\title{
Direitos humanos e antirracismo
}

A proteção dos direitos humanos passou a ter destaque internacionalmente com o fim da II Guerra mundial e as árduas lições deixadas pelo holocausto. Além de proteger os indivíduos expostos a determinadas condições, era preciso proteger todos os seres humanos. Ou seja, quando as vias internas se mostrassem incapazes de salvaguardar esses direitos, seria preciso acionar os instrumentos internacionais de proteção (TRINDADE, 2009).

\begin{abstract}
A experiência internacional em matéria de proteção dos direitos humanos, tem revelado em diferentes momentos históricos, o consenso quanto à universalidade dos direitos humanos, mais além das diferenças quanto a concepções doutrinárias e ideológicas e particularidades culturais. Foi, assim, possível, alcançar uma Declaração Universal no mundo profundamente dividido do pós-guerra; foi igualmente possível, em plena guerra-fria, adotar os dois Pactos de Direitos Humanos em votação à qual concorreram países tanto ocidentais quanto socialistas, com regimes sócio-econômicos antagônicos, sem falar no chamado terceiro mundo. Em meio a tantos antagonismos da época, foi possível afirmar a indivisibilidade de todos os direitos humanos (TRINDADE, 2009, p. 18).
\end{abstract}

A aprovação da Declaração Universal dos Direitos Humanos trouxe a preocupações dos seus signatários no que se refere a efetivação dos direitos humanos no âmbito do direito interno. Preocupações ainda hoje relevantes, tendo em vista os esforços permanentes para tornar concretas a aspirações de justiça e dignidade para todos os seres humanos. O caráter juridicamente vinculante das normas internacionais tem relação com o direito positivo interno, assegurando o respeito e a proteção dos direitos humanos na legislação dos países signatários. Porém, o hiato entre a norma internacional e a sua implementação no direito interno continua a ser um dos temas centrais no debate sobre os direitos humanos (SABOIA, 2009).

Em 2003, foi lançado o Plano Nacional de Educação em Direitos Humanos (PNEDH), com fulcro em documentos nacionais e internacionais, especialmente no Programa Mundial de Educação em Direitos Humanos (PMEDH). Considerando a multiplicidade de subtemas que envolvem a temática dos direitos humanos, elencados no PMEDH, abordaremos tão somente as questões étnico-raciais. Cumpre salientar que as relações étnico-raciais estão imbricadas com os demais temas relacionados aos direitos humanos, mormente, as liberdades fundamentais e a dignidade da pessoa humana. 
O PNEDH entende que a educação é um direito e um meio indispensável para o acesso aos outros direitos, devendo contemplar a valorização e o respeito aos socialmente excluídos, com a finalidade de efetivação da cidadania plena (BRASIL, 2006). Para tanto, será primordial que se construa a cidadania de forma libertadora, com a valorização e o respeito a diversidade, tendo em vista que a escola deve ser um espaço de discussão onde as mais variadas concepções de mundo sejam acolhidas e respeitadas (BRASIL, 2006).

A afirmação dos direitos humanos como universais, indivisíveis e interdependentes é um dos princípios do Estado brasileiro. Nesse sentido, as políticas públicas, desde a promulgação da Constituição Federal de 1988, têm observado a efetivação dos direitos humanos com a finalidade de construir uma sociedade menos desigual. Para tanto, foram observadas demandas antigas e contemporâneas da nossa sociedade para efetivação da democracia, desenvolvimento e justiça social (BRASIL, 2006).

A Constituição Federal de 1988, em seus primeiros artigos, afirma que o Brasil tem como norte a efetivação dos Direitos Humanos, reconhecendo os direitos e as liberdades fundamentais para o alicerce do Estado Democrático de Direito. O Estado brasileiro ratificou, nos últimos anos, os principais instrumentos internacionais de proteção aos direitos humanos, incluindo-os como parte da agenda nacional. A partir disso, foram construídos instrumentos de participação social, com fulcro na democracia participativa. Para efetivação das políticas públicas de igualdade racial foi criada, em 2003, a Secretaria Especial das Políticas de Promoção da Igualdade Racial (VANNUCHI, 2009).

A luta contra o racismo no Brasil vem de longa data. Muito antes da Princesa Isabel firmar o documento que libertou os escravizados, já existiam movimentos que lutavam pelo fim da escravidão. A resistência negra, "que se concretizou em muitas revoltas, fugas e formação de quilombos em grande parte do território nacional” (SOUZA, 2009, p. 154), foi o início desse processo. Os negros foram libertados da escravidão, porém, continuaram excluídos, ou seja, sem acesso ao trabalho digno e a educação (SOUZA, 2009).

A legislação brasileira, mesmo depois da abolição, apressou-se em discriminar as diversas expressões culturais e identitárias dos grupos negros, como a dança e a religiosidade, as quais foram criminalizados pelo Código Penal de 1890. A primeira constituição republicana, promulgada em 24 de fevereiro de 1891, silenciava-se a respeito do racismo. Limitava-se a dispor, em seu art. 72, ao fato de que "Todos são iguais perante a lei”. Até 1930, não havia nenhuma lei que desse garantias aos negros, especificamente. A 
Constituição de 1934 era clara ao mencionar que não haveria discriminação por questões raciais no Brasil. Já a Constituição de 1937 reproduzia o mesmo texto da Constituição de 1891, frustrando as expectativas da época, referentes a discriminação racial (SOUZA, 2009).

O preconceito e a discriminação racial no Brasil tem sido tema de grandes debates e embates na sociedade brasileira. Ainda assim, existem pessoas que creem na falácia do mito da democracia racial. Alguns grupos chegam a afirmar que as ações afirmativas só fazem crescer o racismo e a discriminação racial, prejudicando as minorias (SOUZA, 2009). A militância negra tem lutado no sentido de transformar a negritude em orgulho. Infelizmente, nos últimos anos, especialmente após 2013, jovens negros forjados em movimentos provenientes de grupos que cultivam ideologias de extrema direita, atacam as conquistas do povo negro em flagrante retrocesso social. Essa prática aponta para o quanto no país ainda são comuns as práticas conservadoras, rendendo o Brasil a condição de subalterno a um modo de produção capitalista-dependente (COSTA, 2017).

As ações afirmativas representam, então, um grande desafio, pois além de corrigir as desigualdades, precisará desconstruir o mito da democracia racial. Nossa população é constituída de 53,5\% de negros e pardos, o que nos faz uma nação mestiça. A igualdade racial deve estar vinculada aos demais programas de desenvolvimento social, pois disso depende, em boa parte, a conquista da cidadania dos grupos que são discriminados sob o ponto de vista étnico e racial (SOUZA, 2009). Nesse sentido, considerando que vivemos sob o modo de produção capitalista, impõe-se que os recursos sejam distribuídos para a correção das desigualdades, traduzindo-os em igualdade de recursos. No modo de produção capitalista, as desigualdades são flagrantes, generalizadas, fazendo-se necessários instrumentos para minorá-las. (BRITO FILHO, 2012).

Não só o Brasil, mas os países da América Latina têm um histórico de violação dos direitos humanos, determinados pela fragilidade do Estado Democrático de Direito e pelas violações constantes dos direitos básicos, como a segurança, a sobrevivência e a identidade cultural (BRASIL, 2006). As políticas públicas de ações afirmativas são importantes para construção de uma sociedade que se pretende igualitária. Por essa razão, as ações afirmativas são pertinentes para o combate das discriminações, no caso em tela, da discriminação racial (BRITO FILHO, 2012).

A consequência jurídica das ações afirmativas se impõe sempre que houver flagrante desigualdade, representando a aplicação do princípio da igualdade, "sempre que 
a realidade apresentar quadros graves de desigualdade" (ROTHENBURG, 2013, p. 3). A doutrina aponta para que onde houver necessidade de tratamento jurídico diverso, em prol da diminuição das desigualdades, não há que se falar em tratamento discriminatório ou desigual em relação àqueles que sempre foram privilegiados (ROTHENBURG, 2013).

No liberalismo, o direito do indivíduo se sobrepõe ao direito do Estado, que ocuparse-á com a proteção da autonomia individual, garantindo a livre determinação de cada um dos seus integrantes (ESTEVÃO, 2015). Porém, o neutralismo do Estado liberal provocou inúmeras injustiças, sendo inevitável mecanismos para o ajuste das necessidades sociais, de forma mais ampla (SILVA, 1992). As ações afirmativas vêm cumprir a justiça social para aqueles que sofreram toda a sorte de injustiças e discriminação, são normas que buscam proporcionar a igualdade real entre os indivíduos (BRITO FILHO, 2012).

A busca por igualdade real, por parte da população negra, não é exclusividade do Brasil. As ações afirmativas surgiram nos Estados Unidos, não como um presente da classe hegemônica branca, mas como uma conquista do movimento negro após décadas de luta por direitos civis. Após a III Conferência Mundial contra o Racismo, a Xenofobia e as Intolerâncias Correlatas, em Durbam, África do Sul, o governo brasileiro lançou o Programa Nacional de Direitos Humanos II, em 2002, um conjunto de medidas que buscaram promover os direitos da população negra (DOMINGUES, 2005).

A reserva de vagas ou cotas raciais para ingresso na educação profissional e tecnológica, continuam a serem debatidas socialmente, apesar do julgamento da ADPF $n^{\circ}$ 186. São as chamadas políticas de ações afirmativas que "visam oferecer aos grupos discriminados e excluídos um tratamento diferenciado para compensar as desvantagens devidas a sua situação de vítimas do racismo e de outras formas de discriminação" (MUNANGA, 2001, p. 31). No Brasil, a política de igualdade racial reservou (lei 12.711/12), de forma proporcional, igual ao mínimo da população de pretos, pardos, indígenas, bem como pessoas com deficiência, vagas para ingresso no ensino superior. A mesma proporcionalidade se aplica ao ensino técnico de nível médio federal, objeto de estudo deste artigo.

Para fins legais, são considerados negros ou negras, as pessoas que se autoclassificam/autodeclaram como pretas e pardas. Na verdade, deve haver uma identificação com o ser negro ou negra, pardo ou parda. Considerar-se-á identidade como um modo de ser e/ou sentir-se, com relação a alguém ou a um grupo, partindo de níveis 
sócio-políticos e históricos de uma sociedade ou de grupo social específico. Essa posição de sujeito permite o compartilhamento de traços culturais e comportamentais expressos através da língua, de rituais, de práticas alimentares e/ou das tradições populares. Portanto, é no âmbito da cultura e da história que as identidades sociais são produzidas (GOMES, 2005).

Nesse sentido, o principal desafio vivido por muitos negros e negras, desde a infância, é o processo de negação de sua negritude, o qual para ser aceito, foi preciso, primeiro, negar-se a si mesmo (GOMES, 2005). Para Fernandes (2017), esse processo de negativa se deu em razão do "ardil da democracia racial fictícia, cuja função é aprisionar o negro dentro de paradoxos que conduzem à negação de si próprio, constrangê-lo a ver-se como ele pensa que é visto pelos brancos" (p.45).

Isso decorre do fato de que aqueles que detém os meios de produção, tem o poder de impor a sua forma de pensar e de agir, submetendo os demais, aos quais faltam os meios de produção (MARX; ENGELS, 2009). Para resguardarem suas identidades étnicas, os grupos negros, primeiramente, tiveram que negar seu universo cultural, para depois, transformá-lo (FERNANDES, 2017). Alguns indivíduos têm colocado em xeque a ideia de que, no Brasil, a discriminação racial decorre da condição de classe, mesmo que considerem que ela se dê por razões materiais as quais são expostos os negros (GUIMARÃES, 2012). Entretanto, no Brasil as questões raciais estão diretamente ligadas às questões de classe social.

O conceito de cor, por sua vez, liga-se ao conceito de raça, sendo que este último é tomado de maneira errada. Se depreende então, que há uma ideologia racial, uma suposta hierarquia de raças entre as pessoas, onde uns são supostamente superiores aos outros (GUIMARÃES, 2012).

A democracia racial, seria, portanto, um sistema de orientação político-social, pela qual negros ou mulatos seguiriam a sua trajetória social sem qualquer discriminação social. Seria a normalidade social, pois seguiriam suas trajetórias sem que a cor fosse atributo para a condição social do indivíduo. Porém, a normalidade estaria atrelada a um padrão universal de comportamento, um padrão brasileiro, muito antes que um padrão branco. Diante disso, justificaríamos o fracasso de uns e o sucesso de outros, a partir da narração de das trajetórias (GUIMARÃES, 2012). Estava posta a meritocracia, a melhor forma de livrar 
o modo de produção capitalista da sua responsabilidade sobre as desigualdades socioeconômicas.

Para Fernandes (2017) a discussão é complexa, pois para os negros, democracia quer dizer igualdade. Assim, democracia e igualdade racial seriam sinônimos, ou seja, o negro não deveria sofrer discriminação e preconceito de raça e classe. Para que a democracia racial se efetive, é necessária "uma transformação simultânea de relações raciais e de relações de classes, nas quais se achem envolvidos" (p. 40).

Portanto, para que entendamos a pertinência das ações afirmativas, será preciso compreender o processo histórico que relegou os ex-escravizados a condição de subalternos. Diante disso, será preciso entender a luta travada pelo povo negro em prol da promulgação das leis 10.639/03 e 12.711/12, bem como os fatores históricos que explicam a necessidade das referidas leis, no tempo presente.

\section{As ações afirmativas, discriminação racial e a luta do povo negro por igualdade}

As relações entre negros e brancos e as tensões oriundas desse conflito, não são novidade do Brasil contemporâneo. A busca pela liberdade nos tribunais já estava acontecendo desde 1870, com a conquista de direitos adquiridos pelo costume e aceitação de alguns dos objetivos das lutas dos negros (CHALHOUB, 1990). Durante a escravidão, houve fugas e formação dos quilombos e, a partir da década de 1880, os ânimos se acirraram, com as rebeliões dos escravizados estourando por todo o país. O abolicionismo cresceu legitimando o protesto dos escravizados que ingressavam em juízo com as chamadas ações de liberdade. Eram representados judicialmente por advogados que lutavam pela liberdade dos escravizados nos tribunais. Havia, portanto, juízes que julgavam com imparcialidade os processos de liberdade, enquanto advogados defendiam os cativos (COSTA, E., 2010).

Percebendo que a abolição estava próxima, os senhores passaram a exigir mais e mais dos escravizados. Jornadas carregadas com mais horas de trabalho eram o estopim para as fugas constantes, assim como para os assassinatos de fazendeiros e feitores. Em resposta, os castigos e sevícias se intensificaram. Por outro lado, "o abolicionismo forneceu aos escravizados uma ideologia que, ao mesmo tempo que justificava a revolta deles, condenava a repressão" (COSTA, 2010, p. 115). A situação ficou difícil de ser 
controlada, rebeliões estouravam por todos os lugares e para controlar os ânimos, os escravizados rebeldes eram presos e os castigos eram aumentados (SCHWARCZ: STARLING, 2015).

Enquanto alguns fazendeiros estavam preocupados com o seu direito de propriedade e com a obtenção de mais lucro através da exploração do trabalho escravo, os jovens abolicionistas comprometidos com as ideias liberais, defendiam o fim da escravidão. Rebouças, Patrocínio e Nabuco eram jovens entusiastas da abolição. Nabuco, um dos seus principais teóricos, usou seus textos para a defesa de mensagens liberais. Para ele a escravidão deixava o Brasil fora do progresso, se tornando uma vergonha diante do mundo moderno. A libertação dos escravos seria a libertação do país e o progresso era esperado através da adoção do trabalho assalariado (SKIDMORE, 2012).

A questão era explicada pelo fato de o pensamento burguês europeu do século XIX pautava-se nas convicções daqueles que entendiam que o "trabalho escravo produzia rendimentos inferiores aos do trabalho livre e inibia o desenvolvimento das indústrias" (COSTA, E., 2010, p.16). Aos poucos os fazendeiros passaram a ver os escravos como um capital empatado, pois as despesas com alimentação e vestuário, muitas vezes, eram superiores ao salário de um trabalhador assalariado.

A economia da metade século XIX pedia novos investimentos. Bancos, estradas de ferro e companhias de seguro eram mais atraentes que a agricultura e não dependiam do braço escravo para obtenção do lucro. Assim, o modo de produção capitalista e o pensamento liberal do século XIX foram fundamentais no processo de abolição. Pode-se dizer que foi uma conquista do povo negro, na medida que recebeu apoio das camadas subalternas da população, homens e mulheres, brancos e pobres, livres ou libertos e imigrantes (COSTA, E. 2010).

Era o início de um novo tempo. Um tempo de trabalho assalariado, do qual ficaram alijados os ex-escravizados, pois, os fazendeiros receberam, sem qualquer custo, os imigrantes que tiveram sua vinda financiada pelo poder público. Na verdade, a Coroa apenas facilitou as coisas para os fazendeiros que não precisaram arcar com as despesas oriundas da vinda dos imigrantes (FERNANDES, 2017). Para os ex-escravizados, por sua vez, nada foi fácil: 
uma exploração aviltante. Os abolicionistas deram seus compromissos por terminados. Eles não se soldavam às pessoas dos ex-escravos, mas com o fim da escravidão e o início de uma nova era social, aberta ao trabalho livre, o "progresso" e à aceleração do desenvolvimento urbano-comercial (FERNANDES, 2017, p. 78).

Desde os anos 1930, têm crescido as tensões raciais no Brasil, especialmente em épocas de pouca coesão nacional. Por exemplo, em São Paulo, os imigrantes europeus se organizaram e o regionalismo paulista assumiu contornos separatistas. Os brasileiros mestiços temiam serem excluídos em seu próprio país. Neste contexto, a Frente Negra Brasileira (FNB) surgiu como uma organização étnica, que buscava reafirmar a posição do negro como brasileiro. O recrutamento e a identificação tinham como ponto de partida a “cor" ou a "raça", não estavam preocupados com as tradições afro-brasileiras, que, no entender da FNB, eram os fatores responsáveis pelos estereótipos. Denunciava-se o preconceito de cor, responsável pelo racismo reinante no mundo do trabalho, uma vez que os empregos, preferencialmente, iam para os brancos estrangeiros (GUIMARÃES, 2012).

A FNB surgida na primeira metade do século XX, possuía filiais e grupos homônimos espalhados por diversos estados brasileiros. Tinha um grande nível de organização, mantinha escolas, grupos artísticos, esportivos, departamento jurídico e serviços de saúde, além da publicação de um jornal, “A Voz da Raça”. Na vigência do Estado Novo (1937-45), essa organização negra sofreu forte repressão. Com o final da Ditadura Varguista, o movimento negro ressurgiu com a fundação da União dos Homens de Cor (UHC), que se expandiu por vários estados brasileiros.

O golpe civil-militar de 1964 reprimiu os movimentos negros. Desde a década de 1950, outro grupo importante, o Teatro Experimental Negro defendia uma legislação antidiscriminatória para o Brasil. Abdias Nascimento era a sua principal liderança. Porém com o golpe de 1964, essa liderança negra passou a ser vista como uma ameaça para o governo autoritário que se instalou. O Ato Institucional $n^{\circ} 5$ limitou ainda mais a liberdade de pensamento e expressão, passando a perseguir as lideranças dos movimentos negros. Nascimento então, partiu para o autoexílio nos EUA, em 1968. (DOMINGUES, 2007).

Em 1978, com a fundação do Movimento Negro Unificado (MNU), volta à cena política a luta dos negros por direitos civis. O MNU inspirou-se em lideranças estadunidenses, como Malcon X e Martin Luther King, além de organizações marxistas como a dos Panteras Negras. Internamente, tinha organização marxista, orientação 
trotskista e convergência socialista. Porém, para a Convergência Socialista só com o fim do capitalismo seria possível construir uma sociedade igualitária capaz de superar o racismo (DOMINGUES, 2007).

Na década de 1980, houve uma especialização das entidades, foram criados centenas de grupos afro-brasileiros por todo o território. As mulheres negras sentido falta de espaço, tanto no movimento negro, quanto no movimento feminista, fundaram suas próprias organizações, como o Geledes (SP) e a Associação das Mulheres Negras de Porto Alegre (DOMINGUES, 2008). Assim, de maneira geral, organizou-se a luta de negros e negras pela conquista de direitos inerentes à pessoa humana. Inicialmente lutando pela liberdade, e atualmente, pela igualdade.

Os grupos sociais que foram, e ainda são discriminados historicamente, como é o caso dos negros e negras, sempre enfrentaram maiores dificuldades para acessar os espaços educacionais. Nesse sentido, o Estado, ao implementar as ações afirmativas pela reserva de vagas, reconhece tal discriminação, garantindo a efetivação da igualdade substancial (FRIEDRICH, 2015).

Para além das cotas, precisamos pensar em currículos que descolonizem a História do Brasil, que proponham alterar as visões de mundo, colocando em xeque os "conceitos canonizados no ensino de História e o pensar historicamente no contexto escolar" (CEREZER; RIBEIRO, 2015, p. 103).

\section{Metodologia}

A presente pesquisa partiu da análise do PNEDH e do PMEDH, no que tange as relações étnico-raciais, para a compreensão do processo histórico que relegou os negros a condição de subalternidade, comprovando a necessidade das ações afirmativas.

Os dados foram analisados sob o ponto de vista histórico-crítico, de maneira analítico-descritiva orientada, quando possível, pelo método dialético que supõe a sociedade como um espaço de contradições. Partiu-se da coleta empírica dos dados, para analisá-los descritivamente, conforme proposição teórica do materialismo histórico (NETTO, 2011).

Esse é um método histórico-materialista que analisa as determinações históricosociais de homens e mulheres na sociedade capitalista, a partir de sua existência real. 


\begin{abstract}
O método em Marx é um tipo de pesquisa histórica revolucionária, em sua forma e em seu conteúdo, que busca na luta de classes (essência da sociedade burguesa) a chave para interpretar o futuro em perspectiva histórica e totalizadora, que foge do esquema liberal de ciência aplicada, da qual a classe dominante se utiliza para dominar não só a forma de se fazer ciência, mas as formas de ser e estar no mundo (JUSTINO, 2017, p. 9/10).
\end{abstract}

Sendo assim, análise do PNEDH e o PMEDH foi feita sobre o recorte das questões étnico-raciais, e os dados da pesquisa bibliográfica a partir de suas contradições históricas, típicas da sociedade capitalista.

\title{
CONSIDERAÇÕES FINAIS
}

Mecanismos de busca e defesa dos direitos humanos não são um privilégio do mundo contemporâneo. A luta contra a tirania de uns sobre os outros deu origem aos mecanismos jurídicos de proteção de direitos. Podemos citar, por exemplo, a Declaração dos Direitos do Homem e do Cidadão (1789) e Declaração dos Direitos da Mulher e Cidadã (1791). Com o final da II Guerra Mundial e início da Guerra Fria, os líderes mundiais temiam que a novel ordem mundial pudesse provocar episódios de violação aos direitos humanos. Por tal motivo, os países assinaram a Declaração Universal dos Direitos Humanos, comprometendo-se a cumprir o acordado, no que tange à violação dos direitos humanos.

O Brasil, no período da Ditadura Civil-Militar, violou os direitos humanos. Por isso, a Constituição Federal de 1988, em seu art. $5^{\text {a }}$, tratou de garantir os direitos individuais dos cidadãos. Direitos e garantias que não podem ser alterados nem por emenda constitucional, pois sua revogação ou modificação se torna impossível, haja vista o art. 60,§ $4^{\circ}$, IV da Constituição Federal.

No art. $5^{\circ}$ da Constituição Federal de 1988 trata do princípio da igualdade de todos perante a lei, sem distinções de raça. Ocorre que, após a abolição, não foram dadas oportunidades aos ex-escravizados, promovendo-se uma desigualdade histórica entre brancos e negros. As ações afirmativas são, por isso, mecanismos jurídicos para a diminuição das igualdades sociais, uma vez que do modo de produção capitalista, não se pode esperar a construção de uma sociedade verdadeiramente igualitária.

Os princípios contidos na Constituição Federal, no seu art. $3^{\circ}$, tem como um dos objetivos fundamentais a construção de uma sociedade justa e solidária. Entretanto, não 
basta apenas proporcionar aos alunos cotistas o ingresso nas escolas técnicas e universidades, é preciso que se combata o racismo e a discriminação racial.

O ingresso pelas cotas, em todos os níveis de ensino (Lei 12.711/12), não impede que os direitos humanos sejam desrespeitados, afinal, práticas racistas violam os direitos humanos. Oportunizar para um maior número de pessoas o acesso à educação, tornará a sociedade, na qual vivemos, um pouco mais justa e igualitária. Para além da lei, será necessário educar os meninos e meninas para que não cometam atos racistas, nem naturalizem as condutas racistas de outrem. Há muito a ser feito, a educação em direitos humanos, somada a uma educação antirracista juntamente com as famílias e outros segmentos da sociedade são os reais instrumento de combate ao racismo. A lei, por si só, é um instrumento inócuo quando a sociedade insiste em não cumpri-la ou a cumpre, apenas, por temer eventuais sanções. Será preciso criar uma cultura antirracista para combater o racismo, para o que a educação antirracista se apresenta como fundamental.

\section{REFERÊNCIAS}

BRASIL. Lei 10.639 de 9 de janeiro de 2003. Altera a Lei no 9.394, de 20 de dezembro de 1996, que estabelece as diretrizes e bases da educação nacional, para incluir no currículo oficial da rede de ensino a obrigatoriedade da temática "História e Cultura Afro-Brasileira", e dá outras providências. Disponível em: http://www.planalto.gov.br/ccivil_03/leis/2003/l10.639.htm. Acesso em: 15 abr. 2008

BRASIL. Lei 11.645 de 10 de março de 2008. Altera a Lei no 9.394, de 20 de dezembro de 1996, modificada pela Lei no 10.639, de 9 de janeiro de 2003, que estabelece as diretrizes e bases da educação nacional, para incluir no currículo oficial da rede de ensino a obrigatoriedade da temática "História e Cultura Afro-Brasileira e Indígena". Disponível em: http://www.planalto.gov.br/ccivil_03/_at02007-2010/2008/lei/l11645.htm Acesso em: 15 abr. 2018

BRASIL. Lei 12.711 de 29 de agosto de 2012. Dispõe sobre o ingresso nas universidades federais e nas instituições federais de ensino técnico de nível médio e dá outras providências. Disponível em: www.planalto.gov.br/ccivil_03/_ato20112014/2012/lei/l12711.htm. Acesso em: 15 abr. 2018.

BRASIL. Constituição da República Federativa do Brasil de 1988. Disponível em: http://www.planalto.gov.br/ccivil_03/constituicao/constituicao.htm. Acesso em: 15 abr. 2018

BRASIL, Comitê Nacional de Educação em Direitos Humanos. Plano Nacional de Educação em Direitos Humanos, Brasília, Secretaria dos Direitos Humanos. Ministério da Educação, Ministério da Justiça, UNESCO, 2006. Disponível em: 
http://portal.mec.gov.br/index.php?option=com_docman\&view=download\&alias=2191plano-nacional-pdf\&ltemid=30192. Acesso em: jun. 2018.

FILHO, José Claudio Monteiro de Brito. Ações afirmativas. São Paulo: Editora LTR Itda, 2012.

BOBBIO, Norberto. A era dos direitos. $10^{\mathrm{a}}$ ed. Tradução: Carlos Nelson Coutinho. Rio de Janeiro: Nova edição, 2004.

CAVALLEIRO, Eliane Maria dos Santos. Discriminação racial e pluralismo em escolas públicas da cidade de São Paulo. In: Educação anti-racista: caminhos abertos pela Lei Federal $n^{0}$ 10.639/03. Secretaria de Educação continuada, alfabetização e diversidade, Brasília, 2005.

CEREZER, Osvaldo Mariotto; RIBEIRO, Renilson Rosa. A formação de professores na fronteira: currículo e diversidade étnico-racial nos cursos de licenciatura em História. Mato Grosso, Brasil. In MULLER, T et al (Orgs). Relações étnico-raciais, formação de professores e currículo. Coleção formação de professores \& relações etnico-raciais. São Paulo: Editora Livraria da Física, 2015.

COSTA, Emília Viotti da. A abolição. $9^{\text {a }}$ edição. São Paulo: Editora UNESP, 2010.

CHALHOUB, Sidney. Visões da liberdade: uma história das últimas décadas de escravidão na corte. São Paulo: Companhia das letras, 1990.

DOMINGUES, Petrônio. Ações afirmativas para negros no Brasil: o início de uma reparação histórica. Revista Brasileira de Educação, n. 29, maio/ ago. 2005. p. 164-176.

DOMINGUES, Petrônio. Movimento negro brasileiro: alguns apontamentos históricos. Revista Brasileira de Educação, v. 13, n. 39, set./dez. 2008. Disponível em: www.scielo.br/pdf/tem/v12n23/v12n23a07. Acesso em: 15 abr. 2018

DOMINGUES, Petrônio. Um "templo de luz": frente negra brasileira (1931-1937) e a questão da educação. Revista Brasileira de Educação, v. 13, n. 39, set./dez. 2008.

ESTEVÃO, Carlos Vilar. Direitos humanos, justiça e educação: uma análise crítica das suas relações complexas em tempos anormais, Ijuí: Editora Unijuí, 2015.

FERNANDES, FLORESTAN. O significado do protesto negro. $1^{\text {a }}$ ed. São Paulo: Expressão Popular co-edição Editora da Fundação Perseu Abramo, 2017.

FRIEDRICH, Rafael. Uma proposta de diálogo intercultural na formação para alunos cotistas. Dissertação de mestrado. Universidade Federal de Santa Maria. Centro de Educação. Santa Maria: Programa de pós-graduação em educação, 2015.

GOMES, Nilma Lino. Alguns termos e conceitos presentes no debate sobre relações raciais no Brasil: uma breve discussão. In: Educação anti-racista: caminhos abertos pela Lei Federal 
n 10.639/03, Secretaria de Educação continuada, alfabetização e diversidade, Brasília, 2005 .

GUIMARÃES, Antônio Sérgio Alfredo. Classes, raças e democracia. $2^{\mathrm{a}}$ ed. São Paulo: Editora 34, 2012.

GORCZERVSKI, Clóvis. Direitos humanos, educação e cidadania: conhecer, educar, praticar. Santa Cruz do Sul: EDUNISC, 2009.

JUSTINO, Aline Aparecida. Método em Marx: uma abordagem científica para o serviço social. II Seminário Nacional, trabalho e políticas sociais, UFSC, 23 a 25 de out de 2017. $<$ https://repositorio.ufsc.br/bitstream/handle/123456789/180065/101_00544.pdf?sequence $=1$. Acessado em 15 abr. 2018

MARX, Karl; ENGELS, Friedrich. A ideologia Alemã. $1^{\text {a }}$ edição. Tradução: Álvaro Pina. São Paulo: Expressão Popular, 2009.

MUNANGA, Kabengele. Políticas de ação afirmativa em benefício da população negra no Brasil: um ponto de vista em defesa das cotas. Disponível em: http://www.redalyc.org/html/703/70311216002. Acesso em: 13 abr. 2018

NETTO, José Paulo. Introdução ao estudo do método de Marx. $1^{\text {a }}$ ed. São Paulo: Editora Expressão Popular, 2011.

ROTHENBURG, Walter Claudius. Prefácio. In: MINHOTO, Antônio Celso Baeta. Da escravidão às cotas: $a$ ação afirmativa e os negros no Brasil. $1^{\mathrm{a}}$ ed. Birigui-SP: Boreal Editora, 2013.

SABOIA, Gilberto Vergne. Significado histórico e relevância contemporânea da Declaração Universal dos Direitos Humanos para o Brasil. In: 60 anos da Declaração Universal dos Direitos Humanos: conquistas do Brasil. Org: GIOVANETTI, Andrea. Fundação Alexandre de Gusmão, Brasília, 2009.

SCHWARCZ, Lilia M: STARLING, Heloísa M. Brasil: uma biografia. São Paulo: Companhia das Letras, 2015.

SKDMORE, Thomas E. Preto no branco: raça e nacionalidade no pensamento brasileiro (1870-1930). $1^{a}$ ed. Tradução: Donaldson M. Garschagen. São Paulo: Companhia das Letras, 2012.

SILVA, José Afonso da. Curso de direito constitucional positivo. $9^{\text {a }}$ ed. São Paulo: Malheiros Editores, 1995.

SOUZA, Édson Santos de. A declaração dos direitos humanos e o combate ao racismo no Brasil. In: 60 anos da Declaração Universal dos Direitos Humanos: conquistas do Brasil, Org: GIOVANETTI, Andrea. Fundação Alexandre de Gusmão, Brasília, 2009. 
SOUZA, Jessé. A Elite do atraso: da escravidão à lava-jato. Rio de Janeiro: Leya, 2017.

TRINDADE, Antônio Augusto Cançado. O legado da Declaração Universal dos Direitos Humanos e sua trajetória ao longo das seis últimas décadas (1948-2008). In: 60 anos da Declaração Universal dos Direitos Humanos: conquistas do Brasil, Org: GIOVANETTI, Andrea. Brasília: Fundação Alexandre de Gusmão, 2009.

THOMPSON, Edward P. A formação da classe operária. Tradução: Denise Bottmann. Rio de Janeiro: Paz e Terra, 1987.

VANNUCHI, Paulo de Tarso. Direitos humanos: avanços e problemas no Brasil. In: 60 anos da Declaração Universal dos Direitos Humanos: conquistas do Brasil, Org: GIOVANETTI, Andrea. Brasília: Fundação Alexandre de Gusmão, 2009.

Recebido em: 09/03/2020

Parecer em: 05/07/2020 Aprovado em: 11/02/2021 